\title{
PENILAIAN KONDISI PERKERASAN JALAN BERBASIS PERANGKAT LUNAK PADA RUAS JALAN YOGYAKARTA-MAGELANG
}

\author{
Wan Aswin Winardi \\ MSTT-DTSL FakultasTeknik \\ Universitas Gadjah Mada \\ Yogyakarta \\ Tlp. (0274) 524712 \\ wanlibra15winardi@gmail.com
}

\author{
Agus Taufik Mulyono \\ MSTT-DTSL FakultasTeknik \\ Universitas Gadjah Mada \\ Yogyakarta \\ Tlp. (0274) 524712 \\ agus.taufik.mulyono@ugm.ac.id
}

\author{
Suryo Hapsoro Tri Utomo \\ MSTT-DTSL FakultasTeknik \\ Universitas Gadjah Mada \\ Yogyakarta \\ Tlp. (0274) 524712 \\ suryohapsoro@ugm.ac.id
}

\begin{abstract}
In this study a software-based modeling study that can accommodate the needs to determine the surface conditions of pavement, plan for handling road damage, and predict the remaining life of pavement services. The data used in this study are primary data from the Pavement Condition Index survey on a YogyakartaMagelang road segment Magelang, KM 10+000-KM 11+000, and secondary data, in the form of Surface Distress Index data, International Roughness Index data, and traffic data obtained from the National Road Planning and Supervision of the Special Province of Yogyakarta. The software used in this study is Borland Delphi 7.0 software. From this study, a software called Modrova was produced. This study shows that the Modrova software is valid to use because the resulting error is relatively small.
\end{abstract}

Keywords: road surface conditions, road damage, road pavement, remaining life of road pavement

\begin{abstract}
Abstrak
Pada studi ini dikaji suatu pemodelan berbasis perangkat lunak yang dapat mengakomodir kebutuhan untuk menentukan kondisi permukaan perkerasan jalan, merencanakan penanganan kerusakan jalan, serta memprediksi sisa umur layanan perkerasan jalan. Data yang digunakan pada penelitian ini adalah data primer hasil survei Pavement Condition Index pada ruas jalan Yogyakarta-Magelang, KM 10+000-KM 11+000 dan data skunder, berupa data Surface Distress Index, data International Roughness Index, serta data lalu lintas yang diperoleh dari Perencanaan dan Pengawasan Jalan Nasional Provinsi Daerah Istimewa Yogyakarta. Perangkat lunak yang digunakan pada studi ini adalah perangkat lunak Borland Delphi 7.0. Dari studi ini dihasilkan suatu perangkat lunak yang diberi nama Modrova. Studi ini menunjukkan bahwa perangkat lunak Modrova valid untuk digunakan karena kesalahan yang dihasilkan relatif kecil.
\end{abstract}

Kata-kata kunci: kondisi permukaan jalan, kerusakan jalan, perkerasan jalan, sisa umur perkerasan jalan

\section{PENDAHULUAN}

Desakan terhadap infrastruktur yang selamat, nyaman, aman, dan berkekuatan (mutu) sudah sangat menjadi komoditi penting saat ini. Lajunya pertumbuhan penduduk, sosial kultural, serta ilmu pengetahuan akan berimbas pada laju aktivitas penduduk di dalam suatu wilayah yang bermuara akhir pada tuntutan penyediaan prasarana infrastruktur yang mengutamakan prinsip keselamatan, kenyamanan, keamanan, dan berkekuatan mutu. Pengguna sarana infrastruktur sudah sangat memberlakukan "kritisasi massal" apabila didapatinya infrastruktur yang tidak mengutamakan prinsip-prinsip tersebut. Terlebih lagi untuk insfrastruktur jalan yang melibatkan banyak elemen pengguna, baik itu pengguna kendaraan, 
pejalan kaki, dan sebagainya. Undang-Undang Republik Indonesia Nomor 38 tahun 2004 tentang Jalan, telah mensyaratkan penyelenggaraan jalan yang memenuhi aspek keselamatan, kenyamanan, keamanan, dan kekuatan (mutu) agar diperoleh umur pelayanan yang mendekati umur perencanaan sehingga akan didapatkan efektivitas dan efisiensi biaya pembangunan dan pemeliharaannya.

Prasarana jalan yang terbebani oleh volume lalu lintas yang tinggi dan berulang akan menyebabkan terjadi penurunan kualitas jalan. Sebagai indikatornya dapat diketahui dari kondisi permukaan jalan, baik kondisi struktural maupun fungsionalnya yang mengalami kerusakan. Kondisi permukaan jalan yang mengalami defisiensi atau kerusakan juga memberikan kontribusi terhadap keselamatan pengguna ruas jalan. Terdapat beberapa sistem pengukur kerusakan perkerasan yang dikenal dengan nama Sistem Penilaian Kondisi Kerusakan Perkerasan atau Pavement Condition Index (PCI), Surface Distress Index (Indeks Kerusakan Permukaan), dan Indeks Kerataan Permukaan, yang dinyatakan dengan nilai International Roughness Index (IRI).

Nilai SDI dan nilai PCI bergantung pada subjektivitas surveyor, sedangkan nilai IRI bergantung pada kemampuan alat yang digunakan untuk survei kerataan permukaan jalan. Secara garis besar, nilai PCI didapat dari pembacaan grafik-grafik tertentu sesuai dengan jenis kerusakan perkerasan yang disurvei. Namun akibat pembacaan grafik secara manual, tentunya akan memakan waktu yang cukup lama dibandingkan dengan adanya suatu aplikasi atau pemodelan yang memodelkan hal tersebut. Nilai SDI didapat dari identifikasi kerusakan yang berpedoman pada Peraturan Menteri Pekerjaan Umum Nomor 13/PRT/M/2011, tentang Tata Cara Pemeliharaan dan Penilikan Jalan. Sedangkan nilai IRI didapat dari output dengan bermacam-macam peralatan survei yang digunakan. Adanya pemodelan terhadap ketiga nilai ini diharapkan dapat mempermudah praktisi atau pengambil keputusan dalam menentukan tindakan terbaik untuk memperbaiki kerusakan atau defisiensi jalan tersebut.

Tujuan penelitian ini adalah mengidentifikasikan nilai kondisi permukaan jalan Yogyakarta-Magelang pada ruas KM 10+000 sampai dengan KM 11+000. Hasilnya dapat digunakan untuk penanganan kerusakan permukaan pada STA tersebut, menyediakan suatu pemodelan berbasis perangkat lunak, yang di dalamnya mengakomodir kebutuhan untuk menentukan nilai kondisi permukaan perkerasan dengan menggunakan data PCI, SDI, dan IRI, menyediakan suatu pemodelan untuk kondisi permukaan jalan menggunakan bahasa pemrograman Borland Delphi 7.0, yang di dalamnya memuat penanganan kerusakan baik untuk perkerasan kaku atau lentur, serta menyediakan suatu pemodelan awal yang dapat dikembangkan sampai pada tahapan sisa umur layanan perkerasan jalan.

Mulyono (2007) mengemukakan bahwa kerusakan struktural perkerasan jalan di Indonesia sering terjadi sebelum umur layanan selesai. Karena itu, diperlukan monitoring dan evaluasi pemberlakuan standar mutu yang dibangun sebagai structure logic model yang hierarkis, komprehensif, dan sistemik sebagai suatu alternatif untuk menyempurnakan beberapa konsep model yang sudah ada. Terdapat 5 faktor dominan yang signifikan memenga- 
ruhi pemberlakuan standar mutu secara sistemik, yaitu sumber daya manusia, sosialisasi standar mutu, pencapaian mutu, kekuatan struktural, dan kemantapan jalan.

Penelitian ini diawali dengan melakukan studi pustaka berdasarkan penelitian terdahulu dan referensi atau literatur yang relevan. Pengumpulan data berupa data primer maupun data sekunder dilakukan setelah studi pustaka selesai. Beberapa data yang digunakan merupakan data skunder yang didapat dari Satker Perencanaan dan Pengawasan Jalan Nasional, Provinsi Daerah Istimewa Yogyakarta, yang akan digunakan untuk mengetahui nilai kondisi perkerasan dan lalu lintas di ruas Jalan Magelang-Yogyakarta, tepatnya pada KM 10 \pm 000 sampai dengan KM 11 \pm 000 . Data skunder yang didapat, antara lain, adalah data lalu lintas, berupa Lalu Lintas Harian Rata-Rata (LHR), data IRI, data SDI, dan data histori penanganan. Pelaksanaan survei PCI dilakukan dengan mengukur jenis dan tingkat kerusakan ruas jalan serta dilakukan dokumentasi foto lapangan. Data skunder dan data primer ini menjadi bahan masukan untuk program yang dibuat.

Analisis kondisi perkerasan jalan dilakukan dengan menggunakan metode PCI secara manual. Manual ini dilakukan dengan cara membaca grafik-grafik kerusakan perkerasan sesuai dengan jenis dan tingkat kerusakan untuk mendapatkan nilai kondisi perkerasan. Analisis secara manual juga dilakukan terhadap data SDI, data IRI, dan data LHR.

Analisis data pemodelan yang dilakukan pada studi ini berbasis aplikasi, yang dirancang menggunakan perangkat lunak Borland Delphi 7.0. Pembacaan grafik-grafik PCI dilakukan oleh pemodelan tersebut. Hal yang sama juga dilakukan terhadap data SDI dan data IRI serta data LHR yang merupakan data skunder. Dari analisis akan dihasilkan penilaian kondisi jalan, baik dengan metode PCI, metode SDI, maupun metode IRI serta usulan penanganan kerusakan jalan.

Tahapan validasi program dilakukan untuk mengetahui apakah pemodelan yang dilakukan berhasil atau tidak. Pemodelan dikatakan berhasil apabila dalam uji validasi antara hitungan manual dan hitungan program tidak terdapat perbedaan yang signifikan.

\section{ANALISIS DAN PEMBAHASAN}

Observasi visual dilakukan secara langsung ke lapangan. Setelah menentukan jenis kerusakan, diberikan tanda atau station setiap segmen pengamatan, seperti ditunjukkan pada Gambar 1.

Rekapan nilai Corrected Deduct Value (CDV), nilai PCI, dan kondisi perkerasan dapat dilihat pada Tabel 1. Jenis kerusakan yang banyak terdapat pada ruas jalan yang diamati adalah kerusakan patching, alligator cracking, bump and sags, serta longitudional cracking. Patching merupakan perbaikan pada bagian permukaan perkerasan jalan yang bergelombang dengan cara menambal. Bahan yang digunakan harus mempunyai modulus bahan yang sama dengan bahan pembentuk perkerasan yang lama. Karena penambalan ini bersifat monolit, suatu waktu patching tersebut akan terlepas kembali. Jenis kerusakan alligator cracking terjadi akibat repitisi beban berulang pada lintasan roda, sedangkan 
bump and sags (turun dan naik) terjadi akibat infiltrasi dan penumpukan material dalam retakan yang diikuti dengan pengaruh beban lalu lintas. Komposisi proporsi kerusakan dapat dilihat pada Gambar 2.

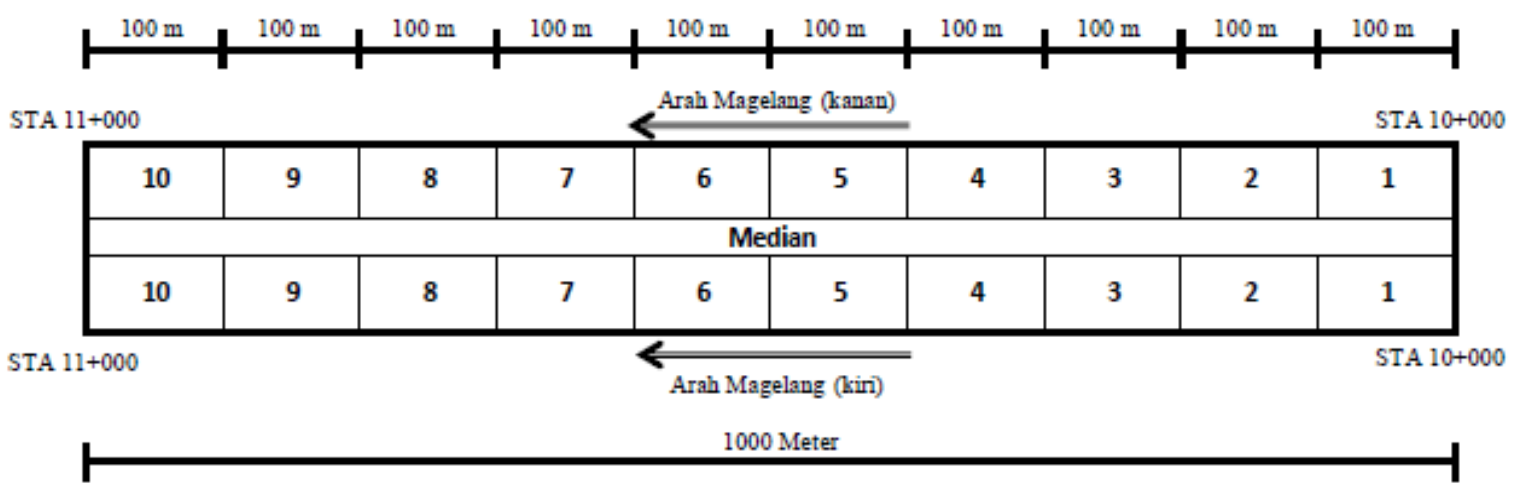

Gambar 1 Penomoran Segmen Jalan

Tabel 1 Nilai PCI dan Kondisi Perkerasan Masing-Masing Segmen

\begin{tabular}{|c|c|c|c|c|c|}
\hline No. STA & Arah & $\begin{array}{c}\text { No. } \\
\text { Segmen }\end{array}$ & $\begin{array}{l}\text { Nilai } \\
\text { CDV } \\
\text { Maks }\end{array}$ & $\begin{array}{c}\text { Nilai } \\
\text { PCI }\end{array}$ & $\begin{array}{c}\text { Kondisi } \\
\text { Perkerasan }\end{array}$ \\
\hline $10+000-10+100$ & Jogja-Magelang (Kanan) & 1 & 0,00 & 100,00 & Sempurna \\
\hline $10+100-10+200$ & Jogja-Magelang (Kanan) & 2 & 0,00 & 100,00 & Sempurna \\
\hline $10+200-10+300$ & Jogja-Magelang (Kanan) & 3 & 0,00 & 100,00 & Sempurna \\
\hline $10+300-10+400$ & Jogja-Magelang (Kanan) & 4 & 14,00 & 86,00 & Sempurna \\
\hline $10+400-10+500$ & Jogja-Magelang (Kanan) & 5 & 20,50 & 79,50 & Sangat baik \\
\hline $10+500-10+600$ & Jogja-Magelang (Kanan) & 6 & 26,20 & 73,80 & Sangat baik \\
\hline $10+600-10+700$ & Jogja-Magelang (Kanan) & 7 & 35,00 & 65,00 & Baik \\
\hline $10+700-10+800$ & Jogja-Magelang (Kanan) & 8 & 35,00 & 65,00 & Baik \\
\hline $10+800-10+900$ & Jogja-Magelang (Kanan) & 9 & 52,00 & 48,00 & Sedang \\
\hline $10+900-11+000$ & Jogja-Magelang (Kanan) & 10 & 4,73 & 94,90 & Sempurna \\
\hline $10+000-10+100$ & Jogja-Magelang (Kiri) & 1 & 18,00 & 82,00 & Sangat baik \\
\hline $10+100-10+200$ & Jogja-Magelang (Kiri) & 2 & 0,00 & 100,00 & Sempurna \\
\hline $10+200-10+300$ & Jogja-Magelang (Kiri) & 3 & 16,00 & 84,00 & Sangat baik \\
\hline $10+300-10+400$ & Jogja-Magelang (Kiri) & 4 & 14,10 & 85,90 & Sempurna \\
\hline $10+400-10+500$ & Jogja-Magelang (Kiri) & 5 & 0,00 & 100,00 & Sempurna \\
\hline $10+500-10+600$ & Jogja-Magelang (Kiri) & 6 & 26,00 & 74,00 & Sangat baik \\
\hline $10+600-10+700$ & Jogja-Magelang (Kiri) & 7 & 0,00 & 100,00 & Sempurna \\
\hline $10+700-10+800$ & Jogja-Magelang (Kiri) & 8 & 10,00 & 90,00 & Sempurna \\
\hline $10+800-10+900$ & Jogja-Magelang (Kiri) & 9 & 7,50 & 92,50 & Sempurna \\
\hline $10+900-11+000$ & Jogja-Magelang (Kiri) & 10 & 40,00 & 60,00 & Baik \\
\hline
\end{tabular}

Setelah pelaksanaan survei kondisi perkerasan di lapangan dan estimasi penentuan kondisi perkerasan jalan dengan metode PCI selesai dilakukan, dilanjutkan dengan kegiatan perbaikan agar efektivitas anggaran dapat terlaksana dalam rangka mencegah timbulnya kerusakan yang lebih parah. Sebaiknya upaya perbaikan ini dilakukan sesegera mungkin pada unit-unit segmen pada ruas jalan Yogyakarta-Magelang yang mengalami kerusakan. Metode perbaikan kerusakan terdapat pada Tabel 3. 


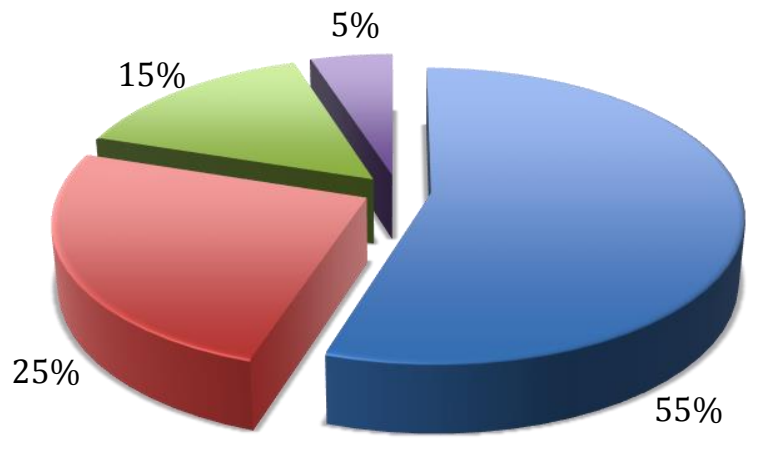

$$
\begin{aligned}
& \square \text { Sempurna (excellent) } \\
& \square \text { Sangat baik (Very good) } \\
& \square \text { Baik (good) } \\
& \square \text { Sedang (fair) } \\
& \square \text { Buruk (poor) } \\
& \square \text { Sangat Buruk (very poor) } \\
& \square \text { Gagal (failed) }
\end{aligned}
$$

Gambar 2 Proporsi Kerusakan Nilai Kondisi Jalan

Tabel 3 Perbaikan Kondisi Perkerasan

\begin{tabular}{clccc}
\hline No. & \multicolumn{1}{c}{ Jenis Kerusakan } & $\begin{array}{c}\text { Tingkat } \\
\text { Kerusakan }\end{array}$ & No. Segmen & $\begin{array}{c}\text { Metode } \\
\text { Perbaikan }\end{array}$ \\
\hline 1 & Alligator cracking & $\mathrm{L}$ & $6,8,11,13,14,18,19,20$ & $\mathrm{P} 1$ \\
2 & Bump and sags & $\mathrm{L}$ & $6,7,8,9,20$ & $\mathrm{P} 1$ \\
3 & Long. and transv. cracking & $\mathrm{L}$ & $4,5,7,8$ & $\mathrm{P} 1$ \\
4 & Patching and utility cut patching & $\mathrm{L}, \mathrm{M}$ & $4,5,6,9,10,14,16,19$ & $\mathrm{P} 5$ \\
5 & Potholes & $\mathrm{L}$ & $9,10,16$ & $\mathrm{P} 5$ \\
\hline
\end{tabular}

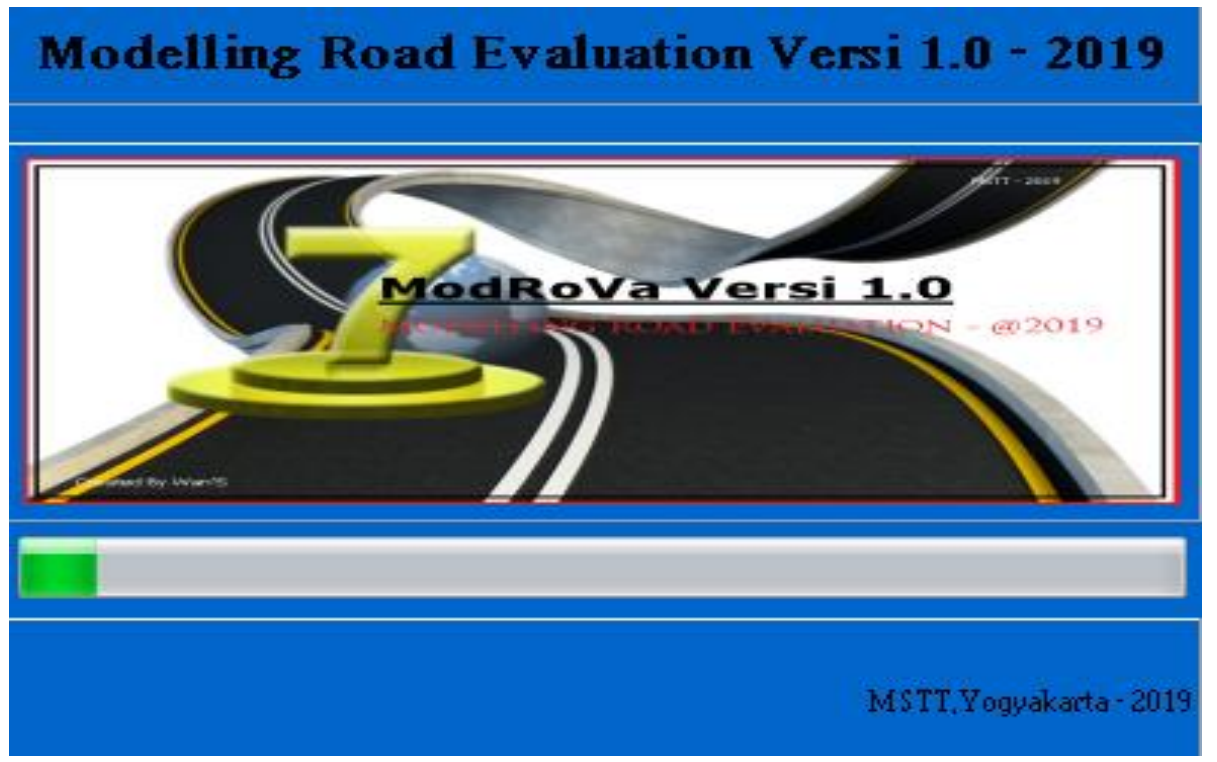

Gambar 3 Tampilan Pembuka Perangkat Lunak Modrova Versi 1.0

Perangkat lunak yang dihasilkan dari penelitian ini bernama Modrova versi 1.0, yang merupakan singkatan dari Modelling Road Evaluation, yang memanfaatkan perangkat lunak Borland Delphi 7.0. Tampilan pembuka Modrova versi 1.0 diperlihatkan pada Gambar 3. Setelah input data dilakukan dengan benar, output kondisi perkerasan dapat dilihat pada 
Gambar 4. Validasi program dilakukan untuk membandingkan nilai manual dan output perangkat lunak Modrova. Validasi program ini dilakukan pada tahapan penentuan nilai Deduct Value (DV) suatu jenis kerusakan yang nilainya merupakan hasil pembacaan dari suatu grafik kerusakan tertentu dan validasi program terhadap Corrective Deduct Value (CDV), yang akhirnya akan memberi nilai PCI suatu ruas jalan. Uji validasi program ini diperlihatkan pada Tabel 4, yang dimaksudkan untuk uji validasi nilai PCI perkerasan lentur.

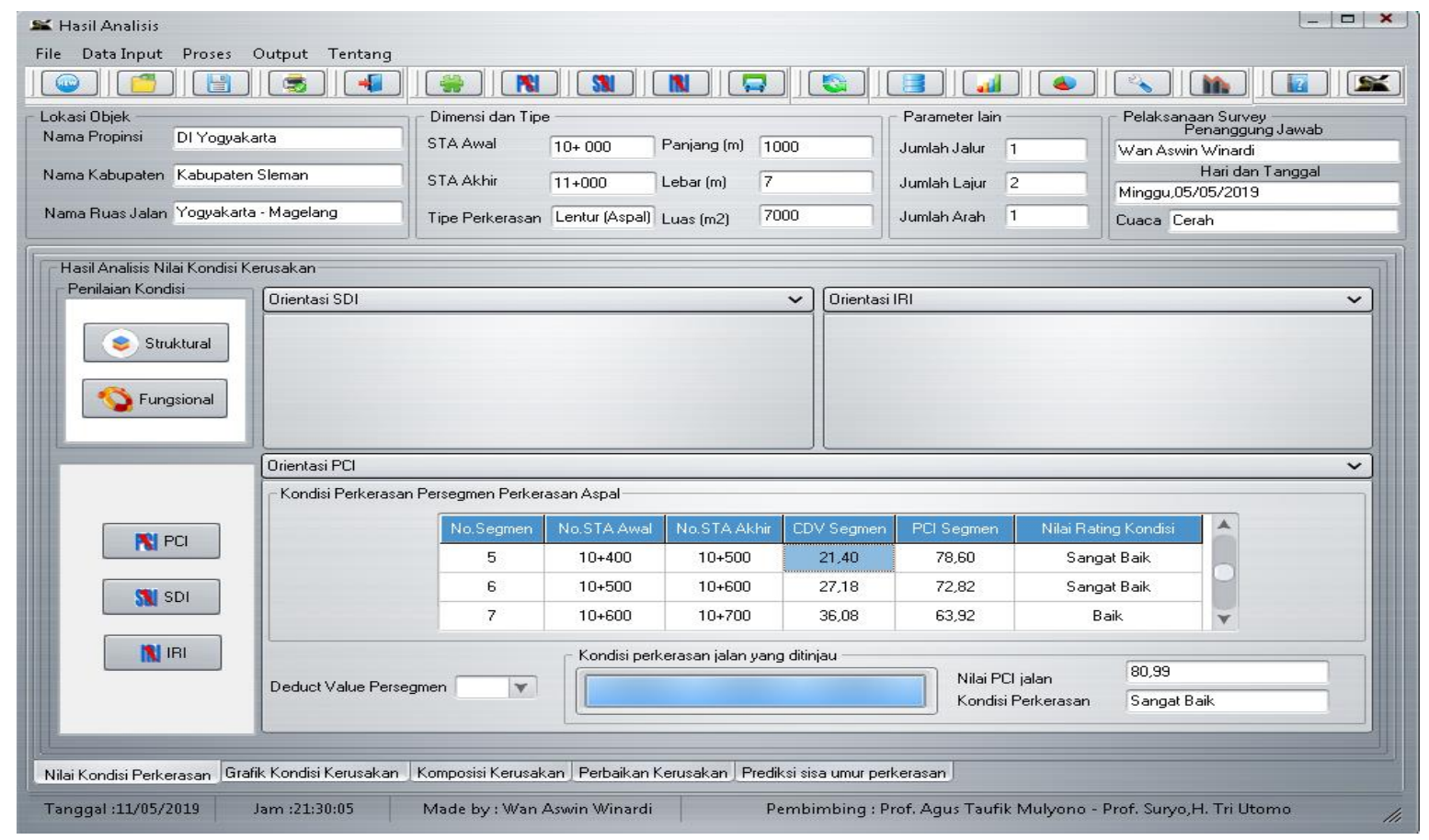

Gambar 4 Output Hasil Analisis

Perbandingan uji validasi nilai PCI disajikan pada Tabel 4. terlihat bahwa bias kesalahan memiliki nilai yang tidak jauh berbeda dengan hasil perhitungan secara manual. Angka terbesar bias kesalahan adalah 2,79\%, yang menunjukkan bahwa perhitungan yang dilakukan dengan menggunakan perangkat lunak aplikasi Modrova memberikan hasil yang cukup baik. Timbulnya bias kesalahan pembacaan dari kurva jenis kerusakan dan kurva Total Deduct Value (TDV) dapat terjadi karena pembacaan kurva cenderung mengambil nilai penuh atau nilai integer, akibat skala kurva jenis kerusakan dan kurva TDV yang menjadi acuan pembacaan tidak mempunyai skala yang jelas dari kondisi sumber asli.

Tampilan output untuk hasil SDI dan IRI dapat dilihat pada Gambar 5 dan Gambar 6 setelah form input terisi dengan benar. Output perangkat lunak Modrova untuk jenis penanganan berdasarkan nilai IRI dan SDI ditunjukkan pada Gambar 7.

Besaran bias kesalahan antara hasil perangkat lunak Modrova dengan hasil perhitungan manual untuk penentuan Remaining Service Life (RSL) dapat dilihat pada Tabel 5. Contoh salah satu output perangkat lunak Modrova untuk RSL ditunjukkan pada Gambar 8, dengan menggunakan data hasil penelitian yang telah dilakukan oleh Nugraheni 
et al. (2018). Terlihat pada Tabel 5 bahwa perhitungan sisa umur perkerasan dari perangkat lunak Modrova cukup valid, dengan persentase bias kesalahan yang sangat kecil. Dengan demikian perangkat lunak Modrova versi 1.0 layak digunakan sebagai alat bantu dalam melakukan prediksi sisa umur perkerasan jalan.

Tabel 4 Uji Validasi Nilai PCI (Segmen 1-10) (Kanan-Kiri)

\begin{tabular}{|c|c|c|c|c|c|c|}
\hline $\begin{array}{c}\text { No. } \\
\text { Segmen }\end{array}$ & $\begin{array}{c}\text { No. STA } \\
\text { Awal }\end{array}$ & $\begin{array}{c}\text { No. STA } \\
\text { Akhir }\end{array}$ & $\begin{array}{c}\text { Manual } \\
\text { PCI Segmen }\end{array}$ & $\begin{array}{c}\text { Software } \\
\text { PCI Segmen }\end{array}$ & Selisih & Persentase \\
\hline \multicolumn{7}{|c|}{ Bagian Kanan } \\
\hline 1 & $10+000$ & $10+100$ & 100,00 & 100,00 & 0,00 & $0,00 \%$ \\
\hline 2 & $10+100$ & $10+200$ & 100,00 & 100,00 & 0,00 & $0,00 \%$ \\
\hline 3 & $10+200$ & $10+300$ & 100,00 & 100,00 & 0,00 & $0,00 \%$ \\
\hline 4 & $10+300$ & $10+400$ & 86,00 & 85,26 & 0,74 & $0,86 \%$ \\
\hline 5 & $10+400$ & $10+500$ & 79,50 & 78,60 & 0,90 & $1,13 \%$ \\
\hline 6 & $10+500$ & $10+600$ & 73,80 & 72,82 & 0,98 & $1,33 \%$ \\
\hline 7 & $10+600$ & $10+700$ & 65,00 & 63,92 & 1,08 & $1,66 \%$ \\
\hline 8 & $10+700$ & $10+800$ & 65,00 & 65,29 & 0,29 & $0,45 \%$ \\
\hline 9 & $10+800$ & $10+900$ & 48,00 & 48,78 & 0,78 & $1,63 \%$ \\
\hline 10 & $10+900$ & $11+000$ & 94,90 & 95,27 & 0,37 & $0,39 \%$ \\
\hline \multicolumn{7}{|c|}{ Bagian Kiri } \\
\hline 1 & $10+000$ & $10+100$ & 82,00 & 81,91 & 0,09 & $0,11 \%$ \\
\hline 2 & $10+100$ & $10+200$ & 100,00 & 100,00 & 0,00 & $0,00 \%$ \\
\hline 3 & $10+200$ & $10+300$ & 84,00 & 84,00 & 0,00 & $0,00 \%$ \\
\hline 4 & $10+300$ & $10+400$ & 85,90 & 83,50 & 2,40 & $2,79 \%$ \\
\hline 5 & $10+400$ & $10+500$ & 100,00 & 100,00 & 0,00 & $0,00 \%$ \\
\hline 6 & $10+500$ & $10+600$ & 74,00 & 73,93 & 0,07 & $0,09 \%$ \\
\hline 7 & $10+600$ & $10+700$ & 100,00 & 100,00 & 0,00 & $0,00 \%$ \\
\hline 8 & $10+700$ & $10+800$ & 90,00 & 90,40 & 0,40 & $0,44 \%$ \\
\hline 9 & $10+800$ & $10+900$ & 92,50 & 93,01 & 0,51 & $0,55 \%$ \\
\hline 10 & $10+900$ & $11+000$ & 60,00 & 59,75 & 0,25 & $0,42 \%$ \\
\hline
\end{tabular}

\begin{tabular}{|c|c|c|c|c|c|}
\hline Orientasi SDI & & & & & $\sim$ \\
\hline No.Segmen & STA Awal & STA Akhir & Nilai SDI & Kondisi Perkerasan & $\widehat{A}$ \\
\hline 1 & $10+000$ & $10+100$ & 55 & Sedang & \\
\hline 2 & $10+100$ & $10+200$ & 57.5 & Sedang & \\
\hline 3 & $10+200$ & $10+300$ & 65 & Sedang & $\nabla$ \\
\hline
\end{tabular}

Gambar 5 Output SDI

\begin{tabular}{|c|c|c|c|c|c|}
\hline \multicolumn{5}{|l|}{ Orientasi IRI } & $\sim$ \\
\hline No.Segmen & STAAwal & STA.Akhir & Nilai IRI & Kondisi Perkerasan & \multirow[t]{3}{*}{ A } \\
\hline 1 & $10+000$ & $10+100$ & 3 & Baik & \\
\hline 2 & $10+100$ & $10+200$ & 3 & Baik & \\
\hline 3 & $10+200$ & $10+300$ & 3,80 & Baik & $\nabla$ \\
\hline
\end{tabular}

Gambar 6 Output IRI 


\begin{tabular}{l} 
Rekomendasi Penanganan Kerusakan Bina Marga \\
\begin{tabular}{|c|c|c|c|c|c|}
\hline Nomor Segmen & STA Awal & STA Akhir & Nilai IRI & Nilai SDI & Penanganan \\
\hline 1 & $10+000$ & $10+100$ & 3 & 55 & Pemeliharaan Rutin \\
\hline 2 & $10+100$ & $10+200$ & 3 & 57,5 & Pemeliharaan Rutin \\
\hline 3 & $10+200$ & $10+300$ & 3,80 & 65 & Pemeliharaan Rutin \\
\hline 4 & $10+300$ & $10+400$ & 3 & 55 & Pemeliharaan Rutin \\
\hline 5 & $10+400$ & $10+500$ & 3,90 & 55 & Pemeliharaan Rutin \\
\hline 6 & $10+500$ & $10+600$ & 3,60 & 55 & Pemeliharaan Rutin \\
\hline 7 & $10+600$ & $10+700$ & 2,10 & 55 & Pemeliharaan Rutin \\
\hline 8 & $10+700$ & $10+800$ & 2,10 & 55 & Pemeliharaan Rutin \\
\hline 9 & $10+800$ & $10+900$ & 2,30 & 55 & Pemeliharaan Rutin \\
\hline
\end{tabular} \\
\hline
\end{tabular}

Gambar 7 Penentuan Jenis Penanganan Menggunakan Perangkat Lunak Modrova

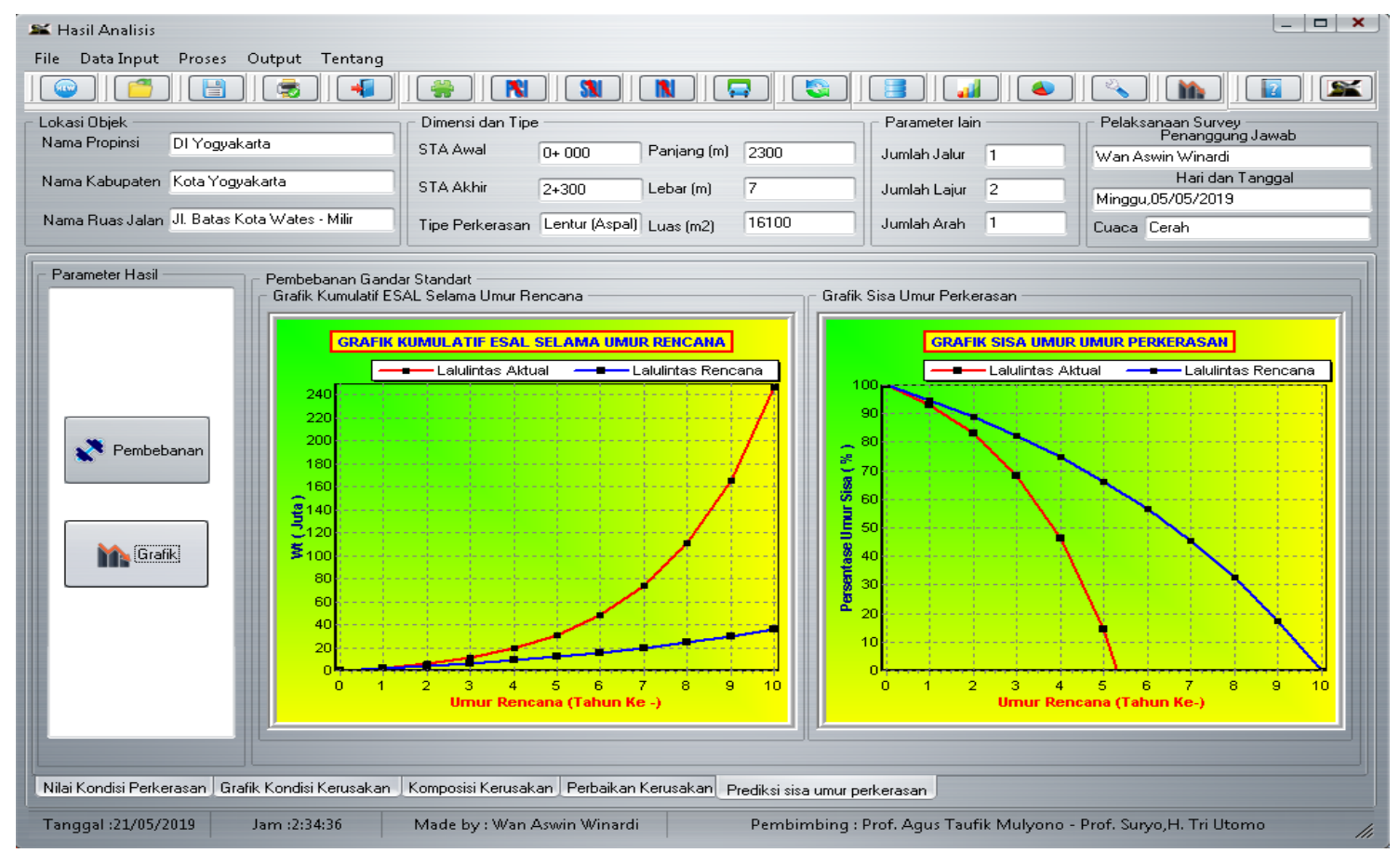

Gambar 8 Output Grafik RSL Perangkat Lunak Modrova Versi 1.0

Tabel 5 Uji Validasi Pembebanan Rencana dan Pembebanan Aktual

\begin{tabular}{|c|c|c|c|c|c|c|c|}
\hline \multirow[b]{2}{*}{ No. } & \multirow[b]{2}{*}{ Tahun } & \multicolumn{6}{|c|}{ Bias Kesalahan Pembebanan Rencana } \\
\hline & & $\begin{array}{c}\text { Selisih } \\
\mathrm{W}_{\mathrm{t}}\end{array}$ & $\begin{array}{c}\% \\
\text { Kesalahan } \\
\mathrm{W}_{\mathrm{t}}\end{array}$ & $\begin{array}{l}\text { Selisih } \mathrm{W}_{\mathrm{t}} \\
\text { Kumulatif }\end{array}$ & $\begin{array}{c}\% \\
\text { Kesalahan } \\
\mathrm{W}_{\mathrm{t}} \text { Kumulatif }\end{array}$ & $\begin{array}{c}\text { Selisih } \\
\text { Remaining } \\
\text { Life }(\%)\end{array}$ & $\begin{array}{c}\text { \% Kesalahan } \\
\text { Remaining } \\
\text { Life }(\%)\end{array}$ \\
\hline 1 & 2013 & 146 & $0,01 \%$ & 146 & $0,01 \%$ & 0,00 & $0,00 \%$ \\
\hline 2 & 2014 & 2350,6 & $0,11 \%$ & 2.497 & $0,06 \%$ & 0,01 & $0,01 \%$ \\
\hline 3 & 2015 & 2160,8 & $0,09 \%$ & 4.657 & $0,07 \%$ & 0,02 & $0,02 \%$ \\
\hline 4 & 2016 & 87,6 & $0,00 \%$ & 4.745 & $0,05 \%$ & 0,02 & $0,02 \%$ \\
\hline 5 & 2017 & 3620,8 & $0,12 \%$ & 1.124 & $0,01 \%$ & 0,01 & $0,02 \%$ \\
\hline 6 & 2018 & 1708,2 & $0,05 \%$ & 584 & $0,00 \%$ & 0,01 & $0,01 \%$ \\
\hline 7 & 2019 & 262,8 & $0,01 \%$ & 847 & $0,00 \%$ & 0,01 & $0,02 \%$ \\
\hline 8 & 2020 & 1489,2 & $0,03 \%$ & 642 & $0,00 \%$ & 0,02 & $0,05 \%$ \\
\hline 9 & 2021 & 2263 & $0,04 \%$ & 1.621 & $0,01 \%$ & 0,01 & $0,08 \%$ \\
\hline 10 & 2022 & 6263,4 & $0,10 \%$ & 7.884 & $0,02 \%$ & 0,00 & $0,00 \%$ \\
\hline
\end{tabular}


Tabel 5 Uji Validasi Pembebanan Rencana dan Pembebanan Aktual (lanjutan)

\begin{tabular}{cccccccc}
\hline & & \multicolumn{5}{c}{ Bias Kesalahan Pembebanan Aktual } \\
\cline { 3 - 7 } No. & Tahun & $\begin{array}{c}\text { Selisih } \\
\mathrm{W}_{\mathrm{t}}\end{array}$ & $\begin{array}{c}\text { Kesalahan } \\
\mathrm{W}_{\mathrm{t}}\end{array}$ & $\begin{array}{c}\text { Selisih } \mathrm{W}_{\mathrm{t}} \\
\text { Kumulatif }\end{array}$ & $\begin{array}{c}\% \\
\text { Kesalahan } \\
\mathrm{W}_{\mathrm{t}} \text { Kumulatif }\end{array}$ & $\begin{array}{c}\text { Selisih } \\
\text { Remaining } \\
\text { Life (\%) }\end{array}$ & $\begin{array}{c}\text { \% Kesalahan } \\
\text { Remaining } \\
\text { Life (\%) }\end{array}$ \\
\hline 1 & 2013 & 453 & $0,02 \%$ & 452,6 & $0,02 \%$ & 0,00 & $0,00 \%$ \\
2 & 2014 & 453 & $0,01 \%$ & 905,2 & $0,01 \%$ & 0,01 & $0,01 \%$ \\
3 & 2015 & 599 & $0,01 \%$ & 1503,8 & $0,01 \%$ & 0,01 & $0,02 \%$ \\
4 & 2016 & 292 & $0,00 \%$ & 1795,8 & $0,01 \%$ & 0,02 & $0,04 \%$ \\
5 & 2017 & 1489 & $0,01 \%$ & 3285 & $0,01 \%$ & 0,03 & $\mathbf{0 , 1 9 \%}$ \\
6 & 2018 & 467 & $0,00 \%$ & 3752,2 & $0,01 \%$ & 0,04 & $0,12 \%$ \\
7 & 2019 & 1460 & $0,01 \%$ & 5212,2 & $0,01 \%$ & 0,06 & $0,06 \%$ \\
8 & 2020 & 4570 & $0,01 \%$ & 9782 & $0,01 \%$ & 0,09 & $0,05 \%$ \\
9 & 2021 & 219 & $0,00 \%$ & 10001 & $0,01 \%$ & 0,13 & $0,04 \%$ \\
10 & 2022 & 2205 & $0,00 \%$ & 12205,6 & $0,00 \%$ & 0,18 & $0,03 \%$ \\
\hline
\end{tabular}

\section{KESIMPULAN}

Hasil penelitian dan pembahasan terkait penilaian kondisi perkerasan jalan berdasarkan PCI, SDI, dan IRI berbasis perangkat lunak adalah sebagai berikut:

1) Pengukuran dan pengamatan secara visual yang dilakukan pada ruas jalan YogyakartaMagelang, STA 10+000 sampai dengan STA 11+000, menunjukkan bahwa terdapat 4 jenis kerusakan utama pada ruas jalan tersebut, yaitu kerusakan berupa alligator cracking, bump and sags, longitudinal and transversal cracking, dan patching and utility patching.

2) Dari penilaian terhadap kondisi perkerasan jalan berdasarkan PCI, SDI, dan IRI pada penelitian ini dihasilkan suatu perangkat lunak aplikasi yang diberi nama Modelling Road Evaluation (Modrova) versi 1.0. Perangkat lunak ini memiliki nilai bias kesalahan yang kecil. Uji validasi terhadap komponen nilai PCI pada perkerasan lentur memberikan nilai bias kesalahan terbesar hanya 2,79\%.

3) Pada uji validasi terhadap Remaining Service Life (RSL) yang menggunakan metode AASHTO 1993, bias kesalahan terbesar terhadap subkomponen remaining life adalah $0,08 \%$ pada pembebanan rencana, dan bias kesalahan terbesar terhadap subkomponen remaining life adalah $0,19 \%$ pada pembebanan aktual.

4) Perbedaan hasil perhitungan yang mengakibatkan timbulnya bias kesalahan pembacaan kurva jenis kerusakan dapat terjadi karena pembacaan kurva cenderung mengambil nilai penuh atau nilai integer, karena kurva jenis kerusakan yang menjadi acuan tidak mempunyai skala yang jelas dari berbagai sumber asli yang didapatkan.

\section{DAFTAR PUSTAKA}

Kementerian Pekerjaan Umum. 2011. Peraturan Menteri Pekerjaan Umum No. 13/PRT/M/ 2011 tentang Tata Cara Pemeliharaan dan Penilikan Jalan. Jakarta. 
Mulyono, A. T. 2007. Model Monitoring dan Evaluasi Pemberlakuan Standar Mutu Perkerasan Jalan Berbasis Pendekatan Sistemik. Disertasi tidak diterbitkan. Semarang: Universitas Diponegoro.

Nugraheni, A.N., Setyawan, A., dan Suryoto. 2018. Analisis Kondisi Fungsional Jalan dengan Metode PSI dan RCI serta Prediksi Sisa Umur Perkerasan Jalan: Studi Kasus Jalan Batas Kota Wates-Milir. E-Jurnal Matriks Teknik Sipil, 6 (1): 105-119.

Pemerintah Repulik Indonesia. 2004. Undang-Undang Republik Indonesia No. 38 Tahun 2004 tentang Jalan. Jakarta. 